\title{
Application of maintenance tools and strategies in integrated risk management of critical physical assets
}

\section{Burnet O’Brien Mkandawire*}

The Polytechnic,

University of Malawi,

Private Bag 303, Blantyre 3, Malawi

E-mail: burnemkanda@hotmail.com

*Corresponding author

\section{Nelson Mutatina ljumba}

HVDC Centre,

University of KwaZulu-Natal,

P/B X54001, Durban 4000, South Africa

E-mail: ijumban@ukzn.ac.za

\section{Howard Whitehead}

Ethekwini Electricity,

322 Cato Road, Glenwood, Durban, 4001, South

Africa E-mail: howardw@mweb.co.za

\begin{abstract}
This paper critically analyses various tools, techniques and strategies; and proposes an 'integrated risk management model' that utilises advantages of the best combination of tools, techniques and strategies to manage risks thereby optimising operating costs whilst maximising returns on critical assets in high voltage networks; and physical assets in general. We used a triangulation method involving a longitudinal single case study within Malawian power sector, multiple (34) industrial case studies and sample surveys of selected Malawian and South African industries. It was shown that the electric power industry $(70 \%)$ lacked a clear systemic maintenance and refurbishment risk management model due to the difficulty in determining optimum combination of tools. They also lacked technical skills needed to apply proactive strategies. The core value of tools is in planning of maintenance and refurbishment; and in contextualising, exploring, assessing, treating and monitoring of risks.
\end{abstract}

Keywords: maintenance; refurbishment; asset management tools; high voltage assets; Malawi; South Africa; integrated risk management.

Reference to this paper should be made as follows: Mkandawire, B.O., Ijumba, N.M. and Whitehead, H. (2011) 'Application of maintenance tools and strategies in integrated risk management of critical physical assets', Int. J. Agile Systems and Management, Vol. 4, No. 3, pp.261-279. 
Biographical notes: Burnet O'Brien Mkandawire is a Lecturer in Automobile Engineering at the Polytechnic College of the University of Malawi. He is a Registered Professional Engineer (REng) with the Malawi Board of Engineers. $\mathrm{He}$ is also a member of the Malawi Institution of Engineers (MMIE). He obtained his MScEng in Electric Power and Energy Systems from the University of KwaZulu-Natal (UKZN) in Durban, South Africa, his BSc in Mechanical Engineering from the University of Malawi and many postgraduate certificates in maintenance of industrial machines and condition monitoring from Germany, India and Japan. His field of interest is sustainable energy resources where he also wants to pursue his $\mathrm{PhD}$ research.

Nelson Mutatina Ijumba is the Vice Chancellor responsible for research at the University of KwaZulu-Natal (UKZN) in Durban, South Africa. He obtained his PhD from the University of Strathclyde in Scotland. He is a Full Professor in High Voltage Direct Current (HVDC) Engineering.

Howard Whitehead is a Practising Engineer, a Fellow of the South African Institute of Electrical Engineers (SAIEE) (FSAIEE), the Honorary Vice President of the SAIEE; and member and Chairman of the Governing Council of the Durban Technical College and the George Campbell Technical High School. He obtained his BSc (Eng) from University of South Africa and he holds an MBL (South Africa). His career spans from 1966-2006; started as an Engineer at Durban Municipality and rose through the ranks to head several departments culminating to Executive Director of Electricity. He served as the Chairman of Natal Branch Committee of SAIEE and the President of Association of Municipal Electricity (AMEU). He has published extensively in South Africa on traffic signalling, electrification; and electricity distribution, restructuring, tariffs and pricing; and prepayment metering. $\mathrm{He}$ is an Infrastructure Management Trainer for Institute of Municipal Engineers of South Africa (IMESA).

\section{Introduction}

This paper was initiated by empirical shortfalls that jeopardised business continuity as observed in the electric power sector in Malawi and South Africa. The paper is case study based with cases from the power sectors, water utilities, manufacturing and government sectors. The power sector case studies included a $132 \mathrm{kV}$ network for Electricity Supply Corporation of Malawi (ESCOM) and a $400 \mathrm{kV}$ network for North West Business unit within Eskom of South Africa. It was noted that maintenance and refurbishment were usually delayed and that there was no clear risk management model for them. It is envisaged that maintenance and refurbishment cannot be separated because "deferred maintenance can lead to repair [refurbishment] costs that are five times the actual maintenance" (Vanier, 2001). Maintenance systems are socio-technical in nature (Kelly, 1997) hence are prone to risks. "The first step in a life cycle asset management strategy is a risk assessment process" (Bartley, 2002). Maintenance techniques are essentially business risk management tools. Hence, this paper uses gaps identified in literature review and empirical study results to assemble an integrated risk management model based on asset management (AM) tools and strategies. Sustainability is a central theme in decision making for operating organisations that pursue long term strategies and risk management tools are pivotal to sustainability. Risks cannot be eliminated completely but 
can be reduced to acceptable levels and the central view of this paper is to establish a model that brings risks associated with physical assets to manageable levels.

Figure 1 The role of asset management in supplying predictive capacity (reliability) (see online version for colours)

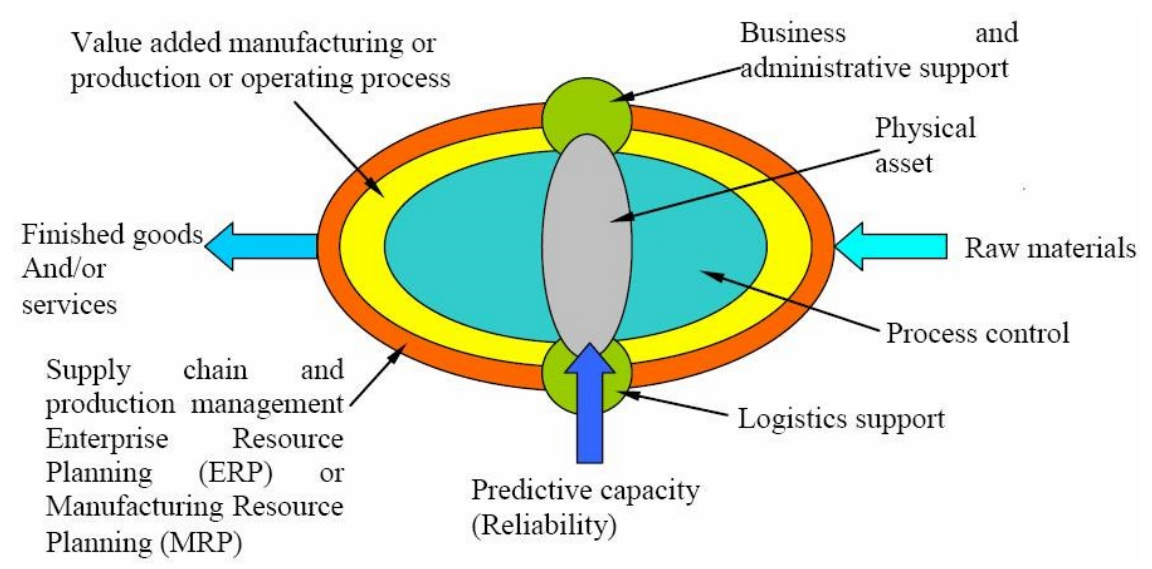

Source: Adapted from Mitchell (2002, p.12)

The key to optimum AM is the systematic elimination of defects or deficiencies before they lead to major damage and interrupt production (Mitchell, 2002). Mitchell (2002, p.12) defines the role of AM as to supply predictable or predictive capacity (reliability) that determines that operating and production equipment are performing with optimal effectiveness and reliability. Mitchell (2002) further propounds that the predictable capacity will be available when required to meet schedule, cost and quality commitments; provide the foresight necessary to evaluate the cost/risk/profit balance of future commitments and opportunities; and demonstrates the concept in the light of a manufacturing process as outlined in Figure 1. There are many benefits of predictable/predictive capacity but two most important ones that relate to refurbishment have been listed as increased asset utilisation and anticipation of equipment ageing effects (Mitchell, 2002). The British Standard Institution (BS3811:1974) defines maintenance as "a combination of any actions carried out to retain an item in, or restore it to an acceptable condition". Maintenance entails all technical and administrative actions intended to restore an item's functionality (Kelly, 1997). Refurbishment is an asset renewal strategy/option/process. It is a means to a goal, which is, achieving AM optimisation. The position or hierarchical level of refurbishment within the AM process has been well defined by Electricity Research Institute (EPRI) as a tactical, asset type of solution to distinguish it from non-asset type of solutions like demand management. Mitchell (2002, p.3) states that, viewed broadly, AM consist of four stages, namely:

a setting business/mission objectives which identify and prioritise opportunities

b constructing a strategy and tactical plans

c injecting processes, systems, technology, and resources

d measuring results in form of reliability or predictable/predictive capacity. 


\section{Methodology}

A literature review was conducted to identify knowledge gaps existing in industries implementing maintenance practices. A longitudinal single case study within ESCOM was used for primary data capture. Triangulation, involving multiple industrial case studies of ten South African and Malawian firms; and a survey of 34 Malawian companies, was employed to provide comparative perspectives with the longitudinal single case study.

\section{Critical evaluation of tools, techniques and strategies}

A critical evaluation of tools, techniques and strategies is necessary before a model can be formulated as it gives insight into their strengths and weaknesses as well as best practices to be employed in the model. It is necessary to apply appropriate tools and strategies for critical assets throughout the life cycle in order to obtain maximum value from them (Mitchell, 2002). High voltage (HV) assets are considered critical assets. An operations and maintenance view of critical assets is defined as "assets for which the financial, business or service level consequences of failure justify proactive inspection and rehabilitation" (IIMM, 2002). AM encompasses the principles of Six Sigma, the balanced score card (BSC), reliability centred maintenance (RCM), reactive [breakdown] maintenance, preventive (periodic) maintenance (PM), condition-based maintenance $(\mathrm{CBM})$, proactive maintenance and financial prioritisation in the decision making process [Mitchell, (2002), p.53]. AM is about optimal equipment management whereby a set of disciplines, methods, procedures and tools are used to optimise the whole life business impact of costs, performance and risk exposure (Woodhouse, 2001). Refurbishment is a means to achieving AM goals, that is, optimisation of the whole life business impact. AM has generally evolved from principles of equipment management. The equipment management has evolved from a largely reactive ('fix it when it breaks') (Mitchell, 2002) approach through PM to CBM and proactive maintenance as shown in Figure 2. Moubray (1997) attaches time frames to concepts associated with the stages of evolution of equipment management propounded by Mitchell (2002) which have been included in Figure 2 in order to adequately distinguish the current maintenance practices from the practices that were superseded over the years in the evolution process. Philosophies and motivations have also been added to capture underlying principles in various stages of evolution.

Four strategies are usually applied in electric utility industries namely: corrective maintenance (CM), time-based maintenance (TBM), CBM, and RCM (Schneider et al., 2006).

CBM leads to high availability with moderate maintenance costs and is mainly applied in extra high voltage (EHV) and HV electric grids but the strategy is slowly being employed in medium voltage (MV) level as well; whereas statistical methods are suitable in low voltage (LV) and MV systems where large number of equipment exists (Schneider et al., 2006).

Electric utilities apply diagnostic and life assessment techniques but these too have shortfalls and/or uncertainties hence corroboratory tests should be carried out to clarify results using another method or tool (Bhumiwat, 2004). For example: return voltage monitoring (RVM) does not correlate transformer moisture content with paper 
degradation as transformer with minimum moisture content may still have poor mechanical integrity. Degree of polymerisation (DP) is invasive and is influenced by ageing. Furan may not be detected at times and there is no universal correlation with DP. Frequency response analysis (FRA) detects transformer winding movement but is unable to indicate mechanical integrity (Vashishtha et al., 1999). Polarisation index (PI) results may be confusing since low PI has been reported for both good and poor insulation condition (Bhumiwat, 2004). Dissolved gas analysis (DGA) reveals gases generated due to degradation, for example: acetylene indicates arcing; hydrogen, partial discharges; ethylene, oil overheating by hot metallic contact; and carbon oxides $\left[\mathrm{CO}\right.$ and $\left.\mathrm{CO}_{2}\right]$ are associated with cellulose degradation but uncertainties still exist when DGA alone is applied. Despite the uncertainties DGA, RVM and DP are considered the best set of testing methods amongst conventional methods for HV AM. These validate the need to evaluate diagnostic techniques before selecting the ones to be applied in an industry.

Figure 2 Evolution of equipment management (see online version for colours)

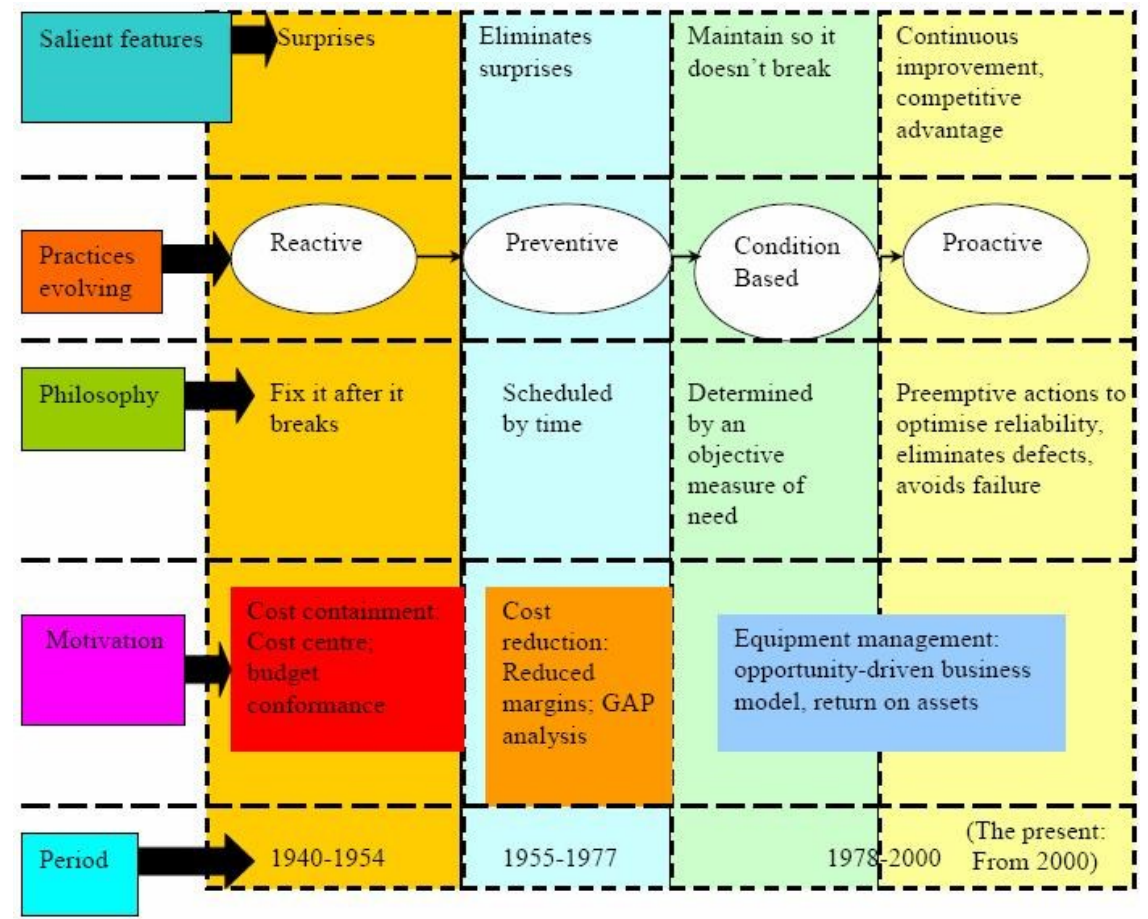

Source: Inspired by Mitchell (2002) and Moubray (1997)

Authors differ on definitions of tools and strategies but they agree on their fundamental role as risk mitigation measures. For example, RCM has been described as a risk management process (August, 2004), as a maintenance organisation (August, 1997) and as a tool (August, 1997; Jana et al., 2006), a methodology (Woodhouse, 2001) and a process (August, 2004; Mitchell, 2002). In this paper, tools are used to describe techniques as well. The suitability of tools depends on the type of industry. For example, RCM is best suited to complex assets/plant and is a very useful tool for establishing maintenance and refurbishment requirements (Woodhouse, 2001; Moubray, 1997). 
However, RCM lacks prioritisation needed for general application in complex manufacturing set up (Mitchell, 2002); it is costly to implement (Moubray, 1997); it needs aspects of total productive maintenance (TPM) to survive and exploit its full potential (Moore and Roth, 1998); it does not provide flexibility and full benefits of probabilistic models (Schwan et al., 2004); and it is not capable of showing quantitative benefits of maintenance for system reliability and costs (Bertling, 2007; Hilber, 2008). Preventive maintenance optimisation (PREMO), based on extensive task analysis rather than system analysis, is claimed to have capability to drastically reduce the required number of maintenance tasks involved in RCM (Areva, 2006). However, PREMO is simply a streamlined form of RCM which means it has similar weaknesses to the RCM. Reliability centred asset management (RCAM) is a quantitative approach specifically developed to compensate for failure of RCM or PREMO so that the benefits of maintenance for system reliability and costs can be included (Bertling, 2007; Hilber, 2008). Despite the shortfalls, RCM has been successfully applied in planning of refurbishment and unit life plans by power utilities and process industries (Mitchell, 2002). The core value of RCM is in answering the questions that need to be asked in order to determine appropriate maintenance strategies (Woodhouse, 2001; Moubray, 1997; August, 2004).

TPM is most suited to manufacturing and automotive industries although it is finding wide industrial application especially in facilitating buy in and loyalty, asset ownership and cultural change (Woodhouse, 2001; Mitchell, 2002; Tajiri and Gotoh, 1992). However, the key tenet of TPM, that is, overall equipment effectiveness (OEE) is flawed in that it is not suitable for benchmarking different types of assets and that its percentage calculations are not statistically valid because they assume that all the equipment related losses are equally important and that any improvement in OEE is a positive improvement for the business, which may not always be true (Williamson, 2006). However, TPM is an important tool set for Six Sigma (Abromowick, 2005) and in instilling cultural change in RCM (Moore and Roth, 1998). Six Sigma was initially established as a system of quality assurance and has been extended to a business and maintenance process directed to increase effectiveness and customer satisfaction and minimises wastes thereby increasing financial returns (Mitchell, 2002).

Total quality management (TQM) and Six Sigma enhance quality in processes, in client focus and in teamwork through multi-disciplined quality circles and improvement activities but they lack rule sets and tools to link diagnosis of a problem to the best solution and the right amount of that solution (Woodhouse, 2001).

Risk-based inspection (RBI), mostly hydrocarbon-industry-focused with wide emerging applications, is a tool that systematically assesses the criticality of static equipment to facilitate choice of appropriate condition monitoring (CM) methods (Woodhouse, 2001). However, the RBI is weaker than the RCM in that it is unable to determine how much to spend on the inspection or condition monitoring (where cost/benefit/risk trade-offs must be considered), and in pointing to the alternative risk treatment options (Woodhouse, 2001).

CBM helps to schedule maintenance as per need and enhances cost effectiveness in the maintenance (Mitchell, 2002). CBM is very applicable to electrical utilities, e.g., in power transformers. However, CBM is restricted to most critical assets such as EHV and HV due to its high initial investment costs (Schneider et al., 2006).

Failure mode effect analysis (FMEA) and failure mode effect and criticality analysis (FMECA) can be performed separately but they are often part of the RCM 
(August, 2004; Moore and Roth, 1998; Keeter, 2003). The FMEA is a procedure that establishes potential failure modes and classifies them according to severity; whereas the FMECA is a procedure by which each potential failure is analysed to determine how the failure is detected and how actions to repair the failure are taken (MIL-STD-1619A). The FMEA and FMECA are good risk prioritisation tools and they help to improve maintenance, safety and efficiency thereby reducing life cycle costs. However, being analytical, their successful application in complex systems entails simplifications such as reduction of failure modes which tend to omit some cascade failures and renders results devoid of systemic view.

TBM or planned PM is best known for preventing outright failure especially where risk and fatalities are to be avoided but almost $50 \%$ of predefined maintenance tasks involved do not add any economic value, are wasteful and do not reveal broad component failure distributions since they base decisions on average values (Mitchell, 2002; Murray, 1999).

Root cause analysis (RCA) applies a number of methodologies to investigate single or multiple failures but its success depends on enablers like motivation, recognition and continuous improvement culture (Moubray, 1997).

Alignment of assets with corporate objectives has been cited as one of the greatest challenges facing asset managers in the power industry (Schneider et al., 2006). Metrics can help in the alignment process by measuring industry performance, operating effectiveness, key performance indicators (KPIs), reliability management, work process efficiency and programme effectiveness, as outlined in Table 1, but selection of the right metric is a challenge if corporate objectives are not clearly set (Mitchell, 2002).

Table 1 Hierarchical representation of metrics, a measure of performance

\begin{tabular}{|c|c|c|}
\hline Metric & Application/significance & Class \\
\hline RONA/ROCE/ROI & $\begin{array}{c}\text { Measure of ability to } \\
\text { create shareholder value }\end{array}$ & Asset/capital \\
\hline Cost as a percentage of CAV or RAV & Measure of industry & Industry \\
\hline Cost per MW or kW or per tonne & performance & performance \\
\hline OEE & Measures of operating & Operating \\
\hline Cost of poor quality (COPQ) & effectiveness & effectiveness \\
\hline $\begin{array}{l}\text { Asset utilisation } \\
\text { Safety indices/no. of fatalities }\end{array}$ & Key performance & KPIs \\
\hline Environmental spillages/violations & indicators & \\
\hline Mean time between failure (MTBF) & Measure of effectiveness & Reliability \\
\hline Availability & of reliability management & management \\
\hline \multicolumn{3}{|l|}{ Mean time to failure (MTTF) } \\
\hline \multicolumn{3}{|l|}{ Mean time to repair (MTTR) } \\
\hline Ratio of planned work to total work done & \multirow{3}{*}{$\begin{array}{l}\text { Measure of work } \\
\text { process efficiency }\end{array}$} & \multirow{2}{*}{$\begin{array}{c}\text { Work process } \\
\text { efficiency }\end{array}$} \\
\hline Overtime as a percentage of total hours worked & & \\
\hline $\begin{array}{l}\text { Store house stock effectiveness } \\
\text { Faults detected prior to failure }\end{array}$ & & \multirow{3}{*}{$\begin{array}{l}\text { Programme } \\
\text { effectiveness }\end{array}$} \\
\hline Faults per km or per $100 \mathrm{~km}$ & \multirow{2}{*}{$\begin{array}{c}\text { Measure of programme } \\
\text { effectiveness }\end{array}$} & \\
\hline Avoided costs & & \\
\hline
\end{tabular}

Source: Adapted from Mitchell (2002, pp.92-114) 
At the top of Table 1 are top-tier metrics which show the ability to create shareholder value, particularly important for members of executive management. All other lower tiermetrics must lead to reinforcement of the top-tier metrics. This can happen if the assets are well aligned with corporate objectives. For example, for repairable components or items mean time between repair (MTBR) is a better measure of reliability than MTBF since poor maintainability results in longer MTBR and therefore extends MTBF for a given MTBR but firms often use MTBF which is wrong (Mitchell, 2002). MTBR is equal to MTBF minus MTTR. For non-repairable components MTTF is phenomenal to MTBR. Similarly, most often power generating industries use effective forced outage rate (EFOR) instead of loss margin which is the most effective (Mitchell, 2002). Other metrics which are similar to loss margin are loss of load expected (LOLE) and loss of energy expected (LOEE) (Billinton and Allan, 1988). The shortfall of EFOR and MTBF is that neither of them is able to identify the ability to operate when required, where the Loss margin is strong; hence the loss margin is a better measure of effectiveness than either EFOR or MTBF (Mitchell, 2002). The way MTBF and MTRR interact to increase equipment availability for both repairable and non-repairable assets and equipment is shown in Figure 3; where availability, $A$ is mathematically presented as:

$$
A=\frac{M T B F}{M T B F+M T T R}
$$

Figure 3 Interaction of mean time between failure and mean time to repair to determine level of availability (see online version for colours)

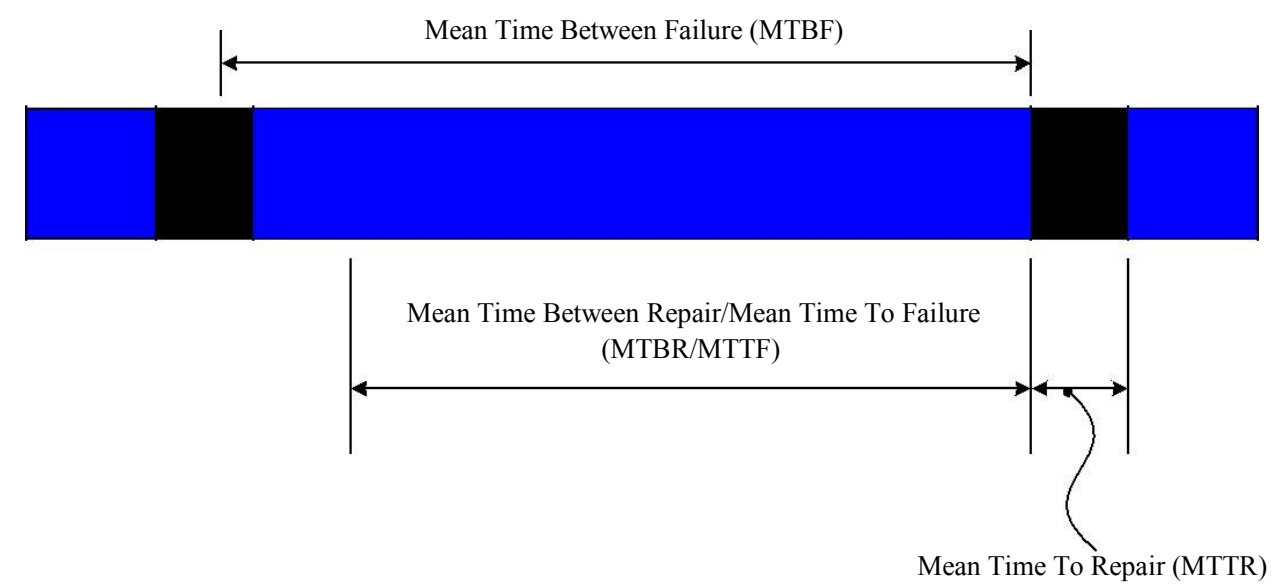

Notes: Mean time between repair (MTBR) applies for repairable items; whereas mean time to failure (MTTF) applies for non-repairable items. To increase availability, MTTR or time to retrofit/replace components should be reduced.

The asset management plan (AMP) is a useful data collection, monitoring and improvement tool (IAM, 2002). The BSC, if correctly used, is a useful top-down method for providing strategic feedback, enhancing shared vision of management teams by presenting strategic performance measures (Mitchell, 2002). Top-down, bottom-up (TDBU) approach is used to review maintenance strategies and life cycle management 
plans (LCMP) by identifying plant operating characteristics and degradation mechanism (Kelly, 1997). Charting techniques such as cause and effect (Ishikawa) diagrams, control bands and Pareto charts can be used for prioritisation and improvement purposes so that efforts are directed to higher value opportunities (Mitchell, 2002; Schuman and Brent, 2005).

Decision support tools (DST) (for operations and maintenance data) are necessary for improving efficiency of AM but their success and selection of the best tools

for refurbishment of a given asset portfolio depend on staff experience, skills, design information and competencies to carry out RCA (Mitchell, 2002). Computerised maintenance management system (CMMS) is a common DST used in industry but it fails to achieve optimisation because although it is capable of storing inventory data, it is incapable of life cycle costing, service life prediction and risk analysis (Vanier, 2001). The major challenge encountered in integration of DST in AM is to optimally link crossfunctions within an organisation; and an open system helps to minimise the challenge as it eliminates the need for proprietary software (Mitchell, 2002).

Operational reliability is a multithreaded improvement strategy (Moubray, 1997) with the capability to optimise integration of people, processes, equipment and technology (Schuman and Brent, 2005). However, it is weak at analytical treatment of equipment data and risk because it heavily depends on maintenance models such as RCM and RBI which do not provide probabilistic modelling required for comprehensive AM (Hilber, 2008). Opportunity driven cost savings (such as safety, reliability, quality) offer quick wins for sustainability (Mitchell, 2002). These can be enhanced by triple bottom line (TBL) (that is, financial, social and environmental bottom-lines) and AM practices in general as a checklist for good corporate governance.

\section{Discussion and analysis of results}

\subsection{Overview of application of tools in industry}

Research results showed that $70 \%$ of the firms employed tools, processes and strategies that are traditional and reactive hence they did not optimise refurbishment. A BSC based on a Likert scale of 1 to 5 for 34 respondents showed that the firms were driven by profitability thereby neglecting issues that ensured sustainability such as development of technical skills base as demonstrated in Figure 4. For example, none of the 34 largest firms (including the electric utility) surveyed nor case studied in Malawi employed RCM for prioritisation of maintenance of their complex assets. Only 6.1\% integrated CBM with PM. Companies that were case studied in South Africa, however, employed RCM or at least stipulated it in their maintenance management frameworks. An AMP is a document outlining the core business assets and risks, maintenance strategies, LCMP, financial management processes, improvement plans; non-asset type solutions, e.g., demand management, insurance, etc., as outlined by IAM (2002). An AMP is important for life cycle management but $94 \%$ of industries in South Africa and Malawi did not have AMPs or mistook documented maintenance programmes for AMPs. These results motivated the development of an integrated refurbishment risk management (IRRM) model that is advanced in this paper. 
Figure 4 BSC showing the need for technical skill base development

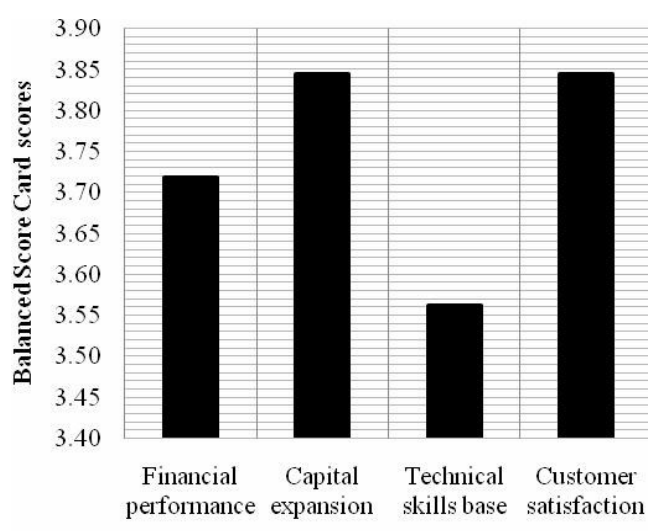

BalancedScore Card attributes

\subsection{Application of tools in risk management model}

Optimum maintenance and refurbishment demands a combination of best tools which is a hard task to accomplish. An IRRM model for refurbishment, shown in Figure 5, is a demonstration of best practice application of AM tools in management of critical assets using the power sector in Malawi and South Africa to validate the model. It is envisaged that the tools can optimise maintenance and refurbishment tasks and projects, respectively, in any industry because it is based on lessons from research results and empirical data drawn from various sectors.

Risk management process has seven stages, namely: risk context, risk identification, risk exploration, risk assessment, monitoring and review; and risk reporting and communication.

This section demonstrates the application of tools that help in the formulation of the IRRM model with reference to Figure 5. In Figure 5, the stages in the IRRM model are clearly represented by stage numbers. Furthermore notes have been added to make the model self explanatory. All core risk management processes have been shown by solid text boxes and solid arrows, whereas all tools have been represented by dotted text boxes and arrows.

Stage 1 is establishment of context and involves establishing boundaries, objectives and functional interactions; establishing and describing key processes and whether anything changed in the environment with time. Tools employed in this stage include TDBU technique as propounded by Kelly (1997) to identify plant operating characteristics, degradation mechanisms (which can be used to review maintenance schedules); to examine windows of opportunity for maintenance and refurbishment; to review existing life management plans so as to form new life plans; to outline metrics to measure performance, for instance, return on investment (ROI) to measure the ability to retain shareholder value and MTBR to measure reliability; to construct a BSC used to provide shared vision and strategic feedback; to employ TQM principles for team-work and process improvement capability; to apply TPM aspects such as autonomous maintenance philosophy for ownership of, buy-in and loyalty to firms facilities and systems. The output from this stage is compilation of the risk landscape that is used in Stage 2. 
Figure 5 IRRM model

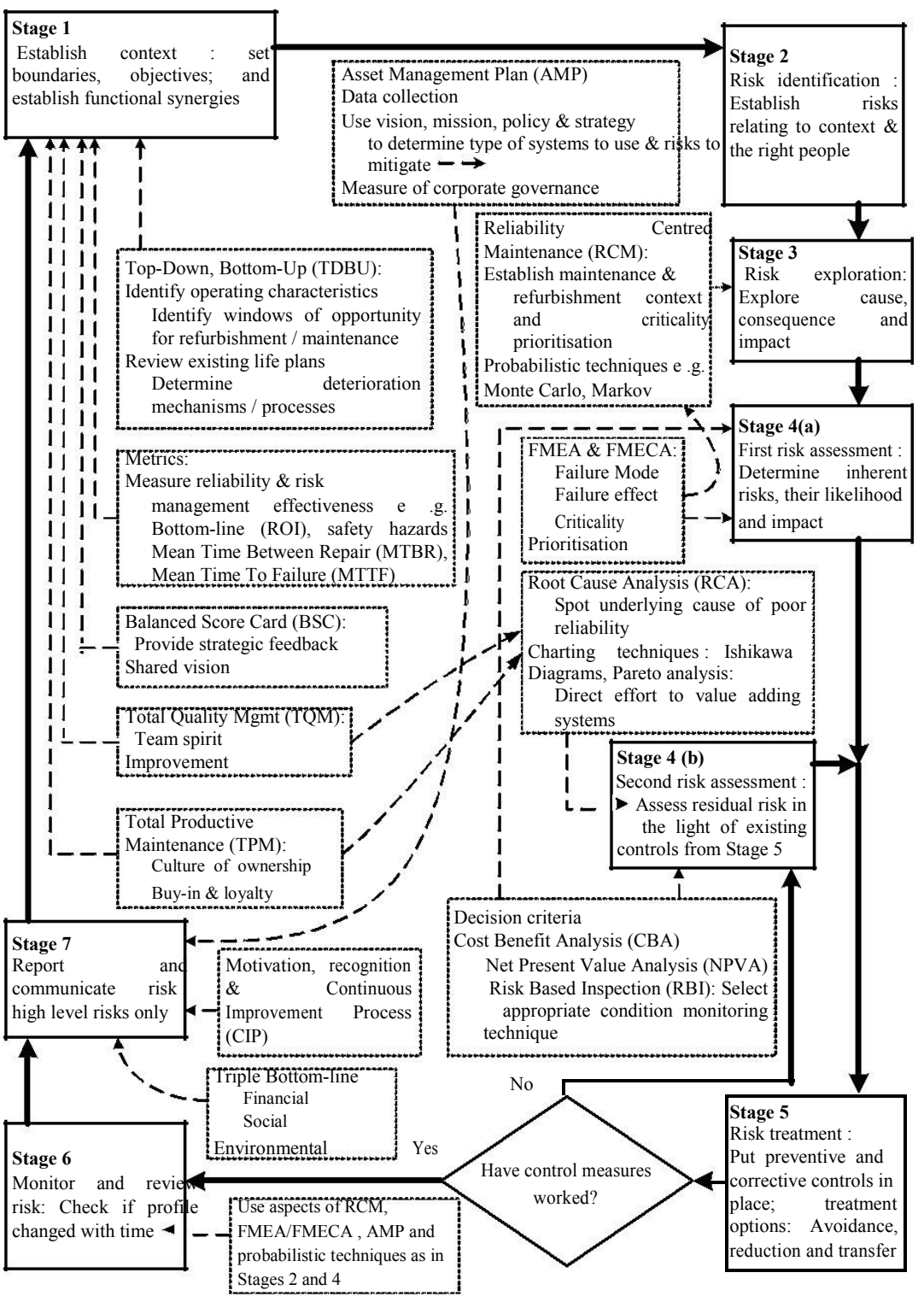

Note: Continuous lines, arrows and boxes for risk management process; doted ones for risk management tools.

Stage 2 is risk identification where risks associated with the context are established and risk champions are identified. In this stage, an AMP plays an important role of data collection, providing vision, mission and strategy that is used to determine the type of systems to use and risks to mitigate. AMP and metrics are necessary for alignment of assets with corporate objectives.

Stage 3 is risk exploration where cause, consequence and impact of risk are explored. For this reason, RCM is employed to establish maintenance and refurbishment 
requirements; to expose hidden and evident failures; and for criticality prioritisation. The RCM also applies other tools such as FMEA and FMECA; hence, there is a link between RCM and FMEA/FMECA in the model. The RCM further provides a concise summary of questions about asset operating context so that appropriate strategies can be formulated such as: in which way does it fail to fulfil its function (failure mode)? What happens when each failure occurs (failure effect)? In which way does each failure matter (failure effect/impact)?

Table 2 FMECA applied to a hydropower plant

\begin{tabular}{|c|c|c|c|c|c|c|c|c|c|c|c|c|c|c|c|}
\hline$A$ & $B C$ & & $D$ & $E$ & $F G$ & $H \quad I$ & & & $J$ & $K$ & $L M$ & $N O$ & $P$ & & \\
\hline 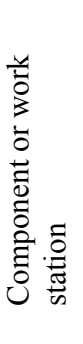 & 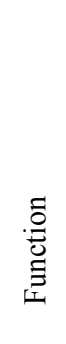 & $\begin{array}{l}\frac{\Xi}{0} \\
\frac{0}{0} \\
0 \\
0\end{array}$ & 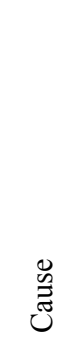 & 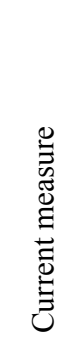 & 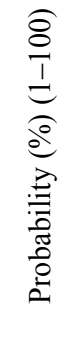 & 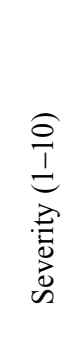 & 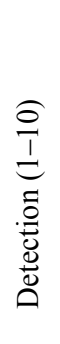 & 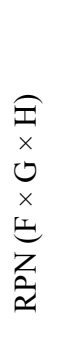 & 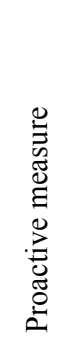 & 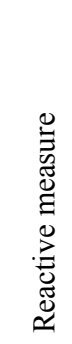 & 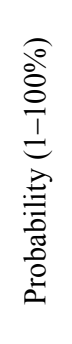 & 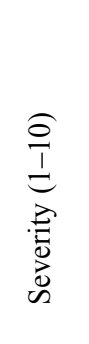 & 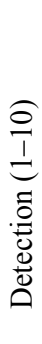 & 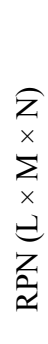 & 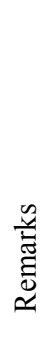 \\
\hline 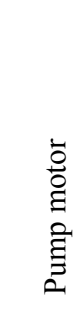 & 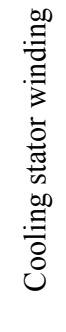 & 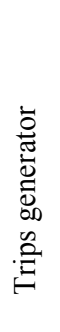 & 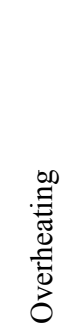 & 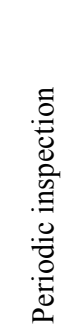 & \& & $a$ & $r$ & $\begin{array}{l}\text { ì } \\
\text { in }\end{array}$ & $\sum$ & 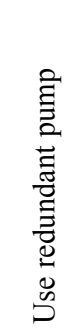 & 으 & $a$ & $N$ & $\stackrel{\infty}{-}$ & \\
\hline
\end{tabular}

Stage 4 is risk assessment. It has been split into two, namely 4(a) and 4(b) because risk assessment is conducted in 4(a), before risk treatment to determine inherent risk and in 4(b), after risk treatment to establish residual risk. Stage 4(a) employs the FMEA and FMECA to provide a vital quantitative means of estimating and rating risks for refurbishment and maintenance purposes as demonstrated in Table 2. The FMECA example (Table 2) is based on a case study of a generator cooling water pump motor for a hydro electric power station at ESCOM. In the table, estimates of probability, severity and detection are respectively, $40 \%, 9 \%$ and $7 \%$. Probability is the likelihood expressed as a percentage (1 to $100 \%$ ). Severity is expressed on a scale of 1 to 10 where 1 is low and 10 is high severity. Severity of impact for a particular subject matter being subjected to risk never changes; for instance a risk that may lead to fatality remains so in any case. Detection is also expressed on a scale of 1 to 10 where 1 means easy to detect such as one that requires an operator to detect; and 10 means most difficult to detect such as one that requires a specialised consultant to detect. In the FMECA (Table 1), the three parameters (probability, severity and detection) should be combined or rated by multiplying them with each other to form a risk priority number (RPN). The estimation and rating should be done based on current measures (before risk treatment) and then repeated after the risk treatment or after proactive measures or controls are executed for comparative evaluation of the risk treatment measures. Closing remarks have been endorsed to evaluate whether 
the measures (from changes in RPN values) are effective or not. From Table 2, the current measures include periodic inspection which results in a RPN of 25.6 but by applying CM as a proactive (control) measure, the RPN reduces to 1.8 . That shows that the proactive measures are very effective. However, reactive measures have also been put in place in form of redundancy in order to increase security against risk of unavoidable failure.

A cost factor, based on premises that some failure modes may have low RPN but are more expensive than those with high RPN (that is, low probability-high consequence failures), can be introduced to weigh the importance of the risk of one plant compared to another as Bartley (2002) showed. Bartley (2002) advances a risk index (RI) instead of RPN. RI is a product of consequence factor $(\mathrm{CF})$ and probability factor (PF) commonly used in power transformers. The RI is expressed as follows:

$$
R I=\text { Consequence Factor }(C F) \times \text { Probability Factor }(P F)
$$

where $C F=($ Cost $\times$ Consequence Index $)$.

In addition, some decision criteria are employed in Stage 4 (a) and 4 (b) to evaluate acceptability of residual risk and in determining whether new risk control measures need to be put in place or not. These criteria are cost benefit analysis (CBA) and net present value analysis (NPVA). Another criterion adopted is RBI. RBI is essentially employed to establish appropriate CM techniques.

Stage 5, risk treatment, comes into action to provide preventive and corrective controls. It is applied to treat the risks assessed in Stage 4 (a). Typically, risk treatment options are avoidance, reduction and transfer. Avoidance should be applied when risk is unavoidable, off-strategy, offers unattractive rewards or when there is no capability to manage risk in the firm. Examples of avoidance strategy include divesture, stopping certain activities or tasks; for example: evaluate technology choices such as solid state instead of transistors; sulphur-hexafluoride $\left(\mathrm{SF}_{6}\right)$ instead of air blast switchgears; or do no maintenance if it costs more than unit replacement. For example, choosing $\mathrm{SF}_{6}$ instead of air blast circuit breakers (CBs) proves to greatly improve safety and reduce operating cost and financial risks as outlined in Table 3 and as further validated by the NPVA that is outlined in Table 4. The NPV approach is the best as it shows the time value of money and considers multi-year budgets. Therefore, NPV is a useful decision criterion for CBA and is thus included in the model.

Table 3 Comparison of OPEX between $400 \mathrm{kV}$ air blast and $\mathrm{SF}_{6}$ circuit breaker technologies (currency in South African Rand, R)

\begin{tabular}{lcc}
\hline $\begin{array}{l}\text { Operation and } \\
\text { maintenance }\end{array}$ & Air blast circuit breaker & SF 6 circuit breaker \\
\hline MOT & One per 12 years at & One per 12 years at \\
& $\mathrm{R} 600,000 \times 11=\mathrm{R} 6,600,000$ & $\mathrm{R} 70,000=\mathrm{R} 770,000$ \\
3\# compressor & Serviced once p.a. at & Nil \\
service per & $\mathrm{R} 360,000 \times 3 \times 12$ yrs $=\mathrm{R} 12,960,000$ & \\
2,000 hrs & One per three years at & Once over four years at \\
PMT & $\mathrm{R} 65,000$ per breaker $\times 11 \times 4=\mathrm{R} 2,860,000$ & $\mathrm{R} 5,000 \times 11 \times 3=\mathrm{R} 165,000$ \\
& & per 12 years \\
\hline
\end{tabular}




\begin{tabular}{|c|c|c|c|c|c|c|c|c|c|c|c|c|}
\hline \multicolumn{13}{|l|}{$\begin{array}{l}\text { Breakers on } \\
\text { PMT cycle }\end{array}$} \\
\hline $\begin{array}{l}\text { A } \\
\text { Breakers on } \\
\text { PMT cycle }\end{array}$ & 3 & & & 3 & & & 3 & & & & & \\
\hline $\begin{array}{l}\text { B } \\
\text { Breakers on } \\
\text { PMT cycle }\end{array}$ & & & 1 & & & 1 & & & 1 & & & 1 \\
\hline $\mathrm{C}$ & & & & 7 & & & 7 & & & 7 & & \\
\hline $\begin{array}{l}\text { Old breaker } \\
\text { unit MOT } \\
\text { cost }\end{array}$ & 600,000 & & & & & & & & & & & \\
\hline $\begin{array}{l}\text { Old breaker } \\
\text { unit PMT } \\
\text { cost }\end{array}$ & 65,000 & & & & & & & & & & & \\
\hline Year & 1 & 2 & 3 & 4 & 5 & 6 & 7 & 8 & 9 & 10 & 11 & 12 \\
\hline $\begin{array}{l}\text { Option } \\
\text { Business as } \\
\text { usual } \\
\text { Breaker }\end{array}$ & & & & & & & & & & & & \\
\hline $\begin{array}{l}\text { MOT } \\
\text { Breaker }\end{array}$ & $4,200,000$ & 0 & 0 & 0 & 0 & 0 & 0 & 0 & 600,000 & $1,800,000$ & 0 & 0 \\
\hline PMT & 195,000 & 0 & 650,00 & 650,000 & 0 & 65,000 & 650,000 & 0 & 65,000 & 455,000 & 0 & 65,000 \\
\hline $\begin{array}{l}\text { Compressor } \\
\text { plant MTCE } \\
\text { Total before }\end{array}$ & 360,000 & 360,000 & 360,000 & 360,000 & 360,000 & 360,000 & 360,000 & 360,000 & 360,000 & 360,000 & 360,000 & 360,000 \\
\hline $\begin{array}{l}\operatorname{tax} \\
\text { Tax credit }\end{array}$ & $4,755,000$ & 360,000 & 425,000 & $1,010,000$ & 360,000 & 425,000 & $1,010,000$ & 360,000 & $1,025,000$ & $2,615,000$ & 360,000 & 425,000 \\
\hline $\begin{array}{l}\text { on OPEX } \\
\text { Total after }\end{array}$ & $-1,378,950$ & $-104,400$ & $-123,250$ & $-292,900$ & $-104,400$ & $-123,250$ & $-292,900$ & $-104,400$ & $-297,250$ & $-758,350$ & $-104,400$ & $-123,250$ \\
\hline & $3,376,050$ & 255,600 & 301,750 & 717,100 & 255,600 & 301,750 & 717,100 & 255,600 & 727,750 & $1,856,650$ & 255,600 & 301,750 \\
\hline $\begin{array}{l}\text { value } \\
\text { Cumulative }\end{array}$ & $3,376,050$ & 241,132 & 268,556 & 602,091 & 202,459 & 225,485 & 505,527 & 169,989 & 456,599 & $1,098,948$ & 142,726 & 158,958 \\
\hline $\begin{array}{l}\text { PV } \\
\text { NPV (old } \\
\text { breakers) }\end{array}$ & $3,376,050$ & $3,617,182$ & $3,885,739$ & $4,487,829$ & $4,690,289$ & $4,915,774$ & $5,421,301$ & $5,591,290$ & $6,047,889$ & $7,146,837$ & $7,289,563$ & $7,448,521$ \\
\hline $\begin{array}{l}\text { New } \mathrm{SF}_{6} \\
\text { breakers } \\
\text { Breaker } \\
\text { MOT unit } \\
\text { cost } \\
\text { Breaker } \\
\text { PMT unit } \\
\text { cost }\end{array}$ & 70,000 & & & & & & & & & & & \\
\hline $\begin{array}{l}\text { Capital cost } \\
\text { Breaker } \\
\text { MOT } \\
\text { Breaker }\end{array}$ & $\begin{array}{c}16,504,432 \\
0\end{array}$ & & & & & & & & & & & \\
\hline $\begin{array}{l}\text { old plant } \\
\text { Total OPEX } \\
\text { before tax }\end{array}$ & 367,000 & 0 & 0 & 0 & 38,500 & 0 & 0 & 0 & 38,500 & 0 & 0 & 0 \\
\hline $\begin{array}{l}\text { Tax credit } \\
\text { on OPEX }\end{array}$ & $-106,430$ & 0 & 0 & 0 & $-11,165$ & 0 & 0 & 0 & $-11,165$ & 0 & 0 & 0 \\
\hline $\begin{array}{l}\text { Depreciation } \\
\text { allowance } \\
\text { Depreciation } \\
\text { allowance } \\
\text { Total after }\end{array}$ & $-1,914,514$ & $\begin{array}{l}-957,257 \\
-957,257\end{array}$ & $\begin{array}{l}-957,257 \\
-957,257\end{array}$ & $\begin{array}{l}-957,257 \\
-957,257\end{array}$ & & & & & & & & \\
\hline $\begin{array}{l}\text { tax } \\
\text { Present }\end{array}$ & $14,850,488$ & $-957,257$ & $-957,257$ & $-957,257$ & 27,335 & 0 & 0 & 0 & 27,335 & 0 & 0 & 0 \\
\hline $\begin{array}{l}\text { value } \\
\text { Cumulative }\end{array}$ & $14,850,488$ & $-903,073$ & $-851,955$ & $-803,731$ & 21,652 & 0 & 0 & 0 & 17,150 & 0 & 0 & 0 \\
\hline PV & $14,850,488$ & $13,947,415$ & $513,095,460$ & $012,291,729$ & $12,313,380$ & $012,313,380$ & $012,313,380$ & $12,313,380$ & $12,330,531$ & $12,330,531$ & $12,330,531$ & $112,330,531$ \\
\hline $\begin{array}{l}\text { NPV (new } \\
\text { breakers) } \\
\text { NPV } \\
\text { difference }\end{array}$ & $\begin{array}{r}12,766,435 \\
-223,398\end{array}$ & & & & & & & & & & & \\
\hline
\end{tabular}




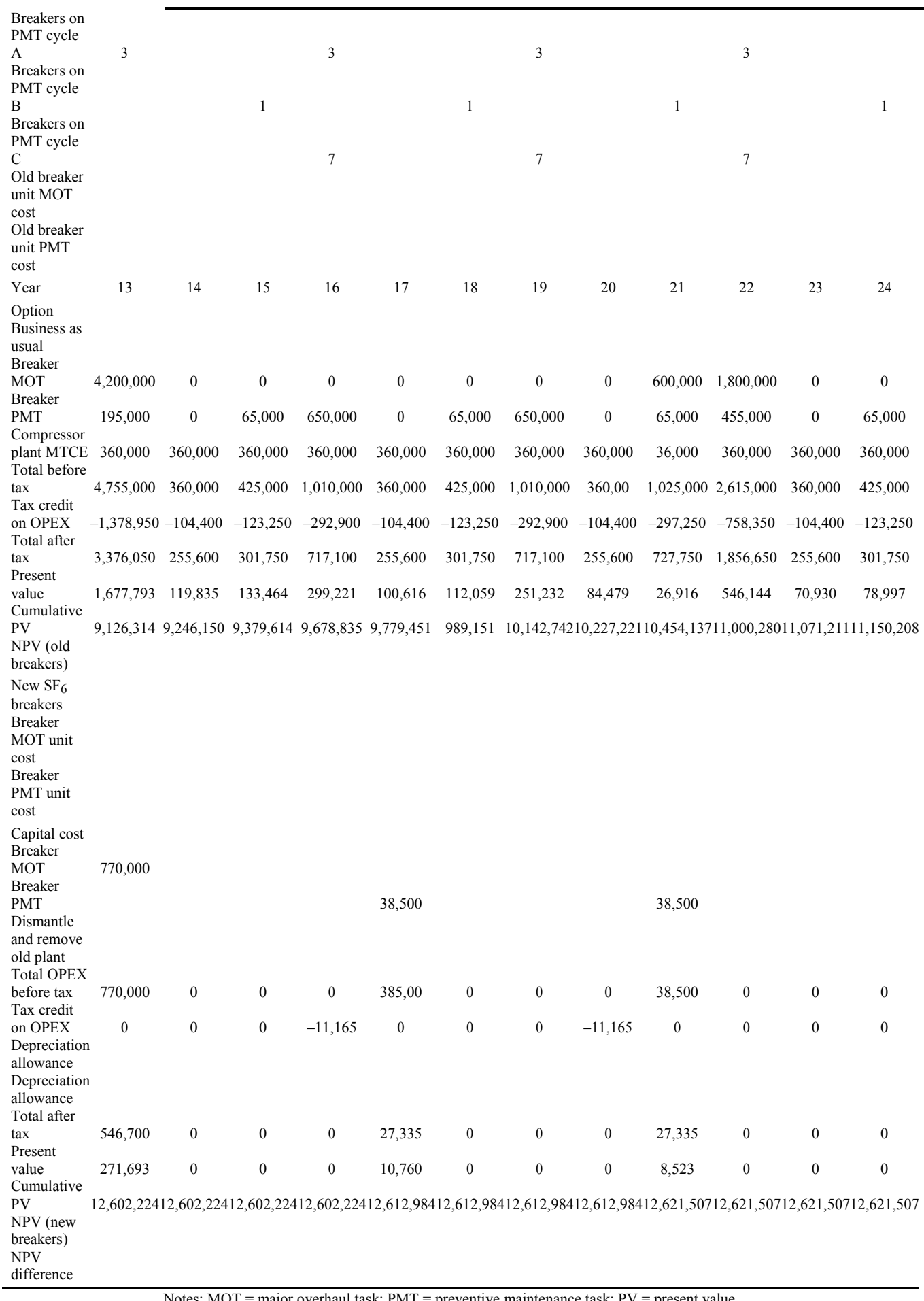

Notes: $\mathrm{MOT}=$ major overhaul task; $\mathrm{PMT}$ = preventive maintenance task; $\mathrm{PV}$ = present value 


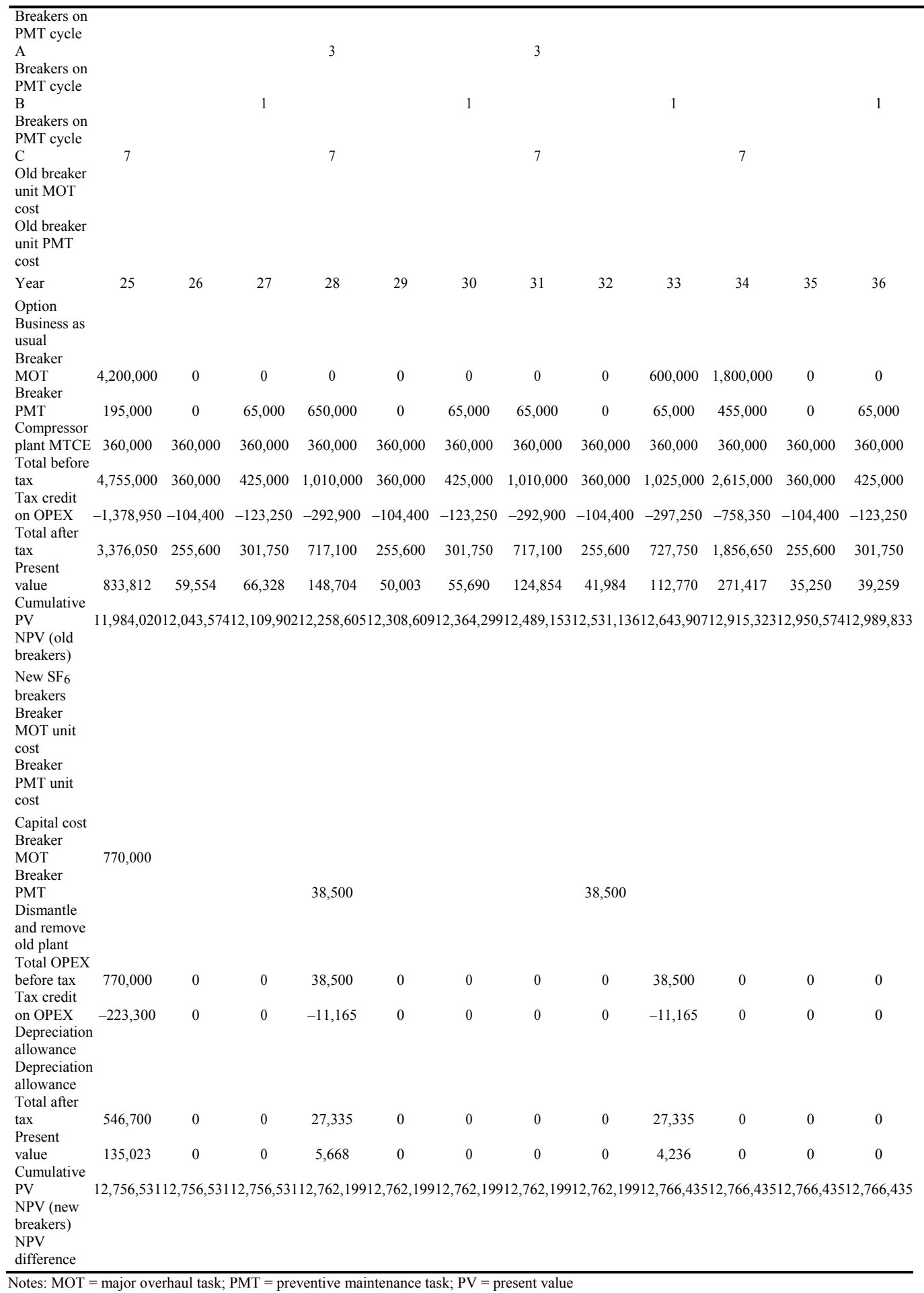


Mathematically, the NPVA is given as:

$$
N P V=-I+\sum_{n=1}^{n=n} \frac{E_{i}-E_{x}}{n}=-I+\sum_{n=1}^{n=n} \frac{\text { Cash Flow }}{n}
$$

where $I=$ initial investment; $E_{i}=$ cash inflow or income; $E_{x}=$ cash outflow or expenditure; $r=$ discount rate; and $n=$ number of years.

For old equipment, NPVA considers costs such that instead of cash inflow, operating expenses and the tax credit on operating cost (OPEX) are used. As expenses, these are exempted from tax in the same way depreciation is exempted thereby raising the cash flow. For analysis of Table 4, assumptions made for the NPVA are: plant life $(n)=36$ years; net discount rate $(r)$ of $6 \%$; and tax rate of $29 \%$ (for tax credit on OPEX). NPVA for OPEX of 11 old CBs based on tax credit on OPEX, preventive or periodic maintenance task (PMT) and major overhaul task (MOT) schedules, for the do nothing (business as usual) approach was R 12,989,833 (South African Rand) and for breaker replacement options based on capital cost of $\mathrm{R} 16,504,432$, PMT and MOT was R $12,766,114$. OPEX savings are found by subtracting the NPV of OPEX for old air blast CBs from the NPV of new $\mathrm{SF}_{6}$ CBs which results in $\mathrm{R} 223,398$ as detailed in Table 4.

Furthermore, on Stage 5, reduction involves control measures that reduce risk likelihood and/or consequences to acceptable levels; for instance training in essential technical skills; fitting surge arrestors, repairing; and non-asset interventions such as load and demand management. Transfer as a risk treatment option entails shifting risk to third party through insurance and contractual arrangements; or shifting assets from place of less importance to those of great strategic importance.

After Stage 5 an important decision box is included in the model, and the question to answer is: have control measures worked? If they have not worked then Stage 4(b), second risk assessment must be executed where RCA is applied to detect the underlying cause of poor reliability. If the measures have worked then Stage 6, monitor and review, is undertaken where periodic reviews and meetings are reinforced by RCM, FMEA and FMECA to prioritise and classify failure consequences. They are also reinforced by AMP to align critical assets with corporate strategy. The purpose of these tools is the same as in Stages 2 and 4.

Stage 7 is the final stage, comprising reporting and communicating risks. Issues of social, financial and environmental sustainability related to the risk profile and management are tackled in this stage. Hence, TBL (social, financial and environmental sustainability) is linked to this stage to provide a checklist for good corporate governance. Specifically, an organisation's management should disclose how its operations have impacted on the environment in terms of disposal of used lubricants and hazardous substances in its annual reporting. The output of the IRRM model is capable of generating and assigning values to risks (risk ranking) which can be used for tracking improvements and benchmarking as validated by senior management of ESCOM.

\section{Conclusions}

It is envisaged that the IRRM model (Figure 5) advanced in the study can apply not only to maintenance and refurbishment processes but also to all AM processes in industries. Output from the IRRM model should be able to generate and assign values to the risks 
analysed in order to form a basis for benchmarking and improvement. This is possible from tools and techniques such as the TDBU approach, FMECA, metrics and strategic solutions such as technology choices. If applied objectively, a BSC can assist companies to get a holistic view of their $\mathrm{AM}$ practices and to leverage change appropriately. Henceforth, maintenance tools, strategies and techniques play an important role in contextualising, exploring and assessing risks so that operating organisations guard against devastating surprises and ensure sustainable business continuity as demonstrated from research and the IRRM model piloting.

\section{Acknowledgements}

The authors are greatly indebted to Technology and Human Resources for Industry Programme (THRIP) of South Africa for funding the study and to management of Sasol Secunda (Mpumalanga) for providing insights into risk management processes.

\section{References}

Abromowick, E. (2005) Six Sigma for Growth: Driving Profitable Top-line Results, pp.44-50, John Wiley and Sons (Asia) Pte Ltd., Singapore.

Areva (2006) The Maintenance PlusTM Process, Areva NP Inc., Charlotte, NC.

August, J.K. (1997) 'Reliability centred maintenance effectiveness in the power Industry: How much is real and how much hype?', Proceedings of the 1997 Joint Power Generation Conference, pp.347-359.

August, J.K. (2004) RCM Guide Book: Building a Reliable Plant Maintenance Programme, PennWell Corporation, Tulsa, Oklahoma.

Bartley, W.H. (2002) 'Life cycle management of utility transformer assets', Paper presented at the Breakthrough Asset Management for the Restructured Power Industry Conference, 10-11 October 2002, Salt Lake City, Utah, The Hartford Steam Boiler Inspection and Insurance Company.

Bertling, L. (2007) 'Tutorial on asset management and replacement strategies', Proceedings of IEEE PES General Meeting, Stockholm, Sweden.

Bhumiwat, S.A. (2004) 'The latest on-site non-destructive technique for insulation analysis of electrical power apparatus', Paper presented at 2004-Weidmann-ACTI Annual Technical Conference, 8-10 November 2004, Sacramento, USA.

Billinton, R. and Allan, R.N. (1988) Reliability Assessment of Large Electric Power Systems, University of Manchester Institute of Science and Technology, Kluwer Academic Publishers, Boston/Dordrecht/Lacanster.

Hilber, P. (2008) 'Maintenance optimisation for power distribution systems', Doctoral thesis, Royal Institute of Technology, Stockholm.

IAM (2002) 'The institute of asset management', International Infrastructure Management Manual, November, 2nd ed., UK.

IIMM (2002) International Infrastructure Management Manual, October 2002, Australia/ New Zealand ed., p.xii, Association of Local Government Engineering, NZ Inc.

Jana, D.R., Banerjee, A. and Sahey, C. (2006) Improving Overall Equipment Effectiveness: A Case Study of the Indian Government Tool Company.

Keeter, B. (2003) 'Using reliability engineering methods as a tool for continuous process improvement', Proceedings of IMC-2003: 18th International Maintenance Conference, Netexpress USA Inc. 
Kelly, A. (1997) Maintenance Strategy, Butterworth-Heinemann, Oxford. MIL-

STD-1619A, Procedures for Performing a FMECA, Military Standards, USA.

Mitchell, J.S. (2002) in Thomas, H.B. and Natalie, N. (Eds): Physical Asset Management Handbook, 3rd ed, Clarion Technical Publishers, Houston, Texas.

Moore, R. and Roth, D. (1998) 'Combining TPM and RCM', Proceedings of Maintenance and Reliability Conference, 12-14 May 1998, Knoxville-Tennessee.

Moubray, J. (1997) Reliability Centred Maintenance, 2nd ed., Butterworth-Heinemann Ltd., Oxford.

Murray, B. (1999) 'Application of risk-based asset management to enhance business performance', Proceedings of Uptime 99: The Gulfs 7th Annual Maintenance Forum, 15-20 May 1999, Dubai.

Schneider, J., Gaul, J., Neumann, C., Hogräfer, J., Wellßow, W., Schwan, M. and Schnetter, A. (2006) 'Asset management techniques', International Journal of Electrical Power and Energy Systems, November, Vol. 28, No. 9, pp.643-654.

Schuman, C.A. and Brent, A.C. (2005) 'Asset life cycle management towards improving physical asset performance in the process industry', International Journal of Operations and Production Management, Vol. 25, No. 6, pp.566-579, ISSN: 0144-3577.

Schwan, M., Weck, K.H. and Roth, M. (2004) 'Assessing the impact of maintenance strategies on supply reliability in asset management methods', Proceedings of the 40th CIGRE Session of August, 2004, Paper C1-108.

Tajiri, M. and Gotoh, F. (1992) TPM Implementation - A Japanese Approach, McGraw Hill, New York.

Vanier, D.J. (2001) 'Why industry needs asset management tools', Journal of Computing in Civil Engineering, January, Vol. 15, No. 1, pp.35-43.

Vashishtha, Y.D., Ascione, P. and Su, Q. (1999) 'The uncertainty in power transformer fault diagnostics using conventional testing methods', Proceedings of Australasian Universities Power Engineering and IE Aust. Electric Energy Conference (AUPEC/EECON'99), 26-29 September 1999, Northern Territory University in Darwin.

Williamson, R.M. (2006) Using Overall Equipment Effectiveness: The Metric and the Measures, Strategic Work Systems, Inc., Columbus.

Woodhouse, J. (2001) Combining Best Bits of RCM, RBI, TPM, TQM, Six-Sigma and Other Solutions, The Woodhouse Partnership Ltd., Newbury, UK. 